\title{
Estimates of global research productivity in using nicotine replacement therapy for tobacco cessation: a bibliometric study
}

\author{
Sa'ed H. Zyoud ${ }^{1,2}$
}

\begin{abstract}
Background: Tobacco use is a major healthcare problem worldwide. Tobacco smoking remains the most important risk factor for both cancer and heart diseases. This study was initiated due to the lack of published data concerning the real progress in research output in the use of nicotine replacement therapy (NRT) for tobacco cessation. This study was aimed to use bibliometric analysis to estimate the NRT literature indexed in Scopus database at global level.

Methods: Core of the search strategy was the documents that contained specific words or phrases regarding NRT as keywords in the title. Publication output of most prolific countries was adjusted to the gross domestic product and population size. All citations analysis were accomplished on December 22, 2017.

Results: A total of 2138 references were retrieved and published from 56 countries, which were published between 1970 and 2016. The USA has the most number of published articles accounted to 986 , followed by the UK (312 publications) and then Australia (102 publications), and Sweden (102 publications). No data related to NRT were published from 156 countries. No significant correlation was found between the country population size or 2016 gross domestic product values and the number of publications of the top-10 most prolific countries in the field of NRT $(r=-0.156, P=0.664$; and $r=-0.173, P=0.632$, respectively). Furthermore, there is no correlation between prevalence of tobacco smoking and number of publications of the top-10 most prolific countries in the field of NRT $(r=-0.235, P=0.514)$.

Conclusions: The present data reveal a solid mass of research activity on NRT. The USA was by far the predominant country in the amount of NRT-based research activity. NRT-based research activities were low or not available in most countries. The results of this study delineate a framework for better understanding the situations of current NRT research and prospective directions of the research in this field which could be applied for managing and prioritizing future research efforts in NRT research.
\end{abstract}

Keywords: Bibliometric, Tobacco smoking, Tobacco cessation, Scopus, Nicotine replacement therapy, NRT

\section{Background}

Tobacco use is a major healthcare problem worldwide. Tobacco smoking remains the most important risk factor for both cancer and heart diseases causing about 6 million deaths and hundreds of billions of dollars burdens at global level each year [1, 2]. The World Health Organisation Framework Convention on Tobacco Control (WHO FCTC) recommends that governments institute broad national tobacco control policies, which

\footnotetext{
Correspondence: saedzyoud@yahoo.com

${ }^{1}$ Poison Control and Drug Information Center (PCDIC), College of Medicine and Health Sciences, An-Najah National University, Nablus 44839, Palestine ${ }^{2}$ Department of Clinical and Community Pharmacy, College of Medicine and Health Sciences, An-Najah National University, Nablus 44839, Palestine
}

should contain the provision of treatment for tobacco dependence, including use of effective smoking-cessation strategies and counselling services [3]. Medication therapy such as nicotine has been shown to help in smoking cessation [4]. This type of medication is called Nicotine Replacement Therapy (NRT) [4]. NRT has been widely accepted as the first-line pharmacological intervention for tobacco dependence because of its safety and efficacy profile [5-7].

Since the development of NRT in 1978, tobacco cessation options have continued to evolve and expand [8]. The aim of NRT is to reduce or prevent withdrawal symptoms related to quitting smoking by substituting 
the nicotine from tobacco smoking to reach complete abstinence from tobacco smoking [9-12]. NRT is available in various forms, e.g. nicotine skin patches, chewing nicotine gum, lozenges/tablets, nasal and oral sprays and inhalers [6, 7]. All forms of NRT were all significantly more effective than placebo, or no NRT, as part of a strategy to promote smoking cessation [6].

Tobacco smoking is on the rise, and since smoking behaviours and consequences involve a multidisciplinary research approach, there is an increasing level of research that includes almost all of worldwide regions that have interested in health sciences production $[13,14]$. Research output has an important function in the scientific development providing a key association between knowledge generation, and use [15]. Although, to the author's knowledge, there were small number of bibliometric studies in the field of tobacco smoking were conducted [2, 14, 16-20], no bibliometric studies have been conducted in the field of NRT. Bibliometric is the application of quantitative analysis method based on statistics and mathematics within a given certain topic [21-23]. This study was aimed to use bibliometric analysis to estimate the NRT literature indexed in Scopus database at global level, and to identify hotspots in research related to NRT. Results from this study will allow researchers to identify the hotspots in NRT which may open doors to new research on the development of effective smoking-cessation strategies and counselling services. Additionally, results delineate a framework for a perceptive recognition of current NRT research and as a result of a realistic advice for decision makers.

\section{Methods}

\section{Search strategy}

The analysis of the scientific research output in this bibliometric study was based on previous bibliometric studies [2, 14, 24-27]. Scopus database was used as the source to retrieve all the bibliometric data regarding the research output in the field of NRT. The Scopus database was used because it is the largest citation and abstract database of peer-reviewed Journals, and it is one of the most reliable databases for publications and citations. Moreover, this database has been widely used in several bibliometric studies in the field of tobacco use $[2,14,19,28]$. Furthermore, Scopus database has been commonly employed in several bibliometric analyses due to combining in the characteristics of both Web of Science and PubMed [29-34].

Documents were selected including the keywords related to NRT that were chosen from previous studies may have been reviews, practical reporting or metaanalyses [6, 35-41]. Keywords used are: 'nicotine replacement', 'NRT', 'nicotine patches', 'nicotine gum', 'nicotine transdermal', 'nicotine medications', 'Nicotinell', 'Nicoderm,' 'nicotine chewing,' 'nicotine pastilles,' 'nicotine delivery system,' 'Nicorette,' 'medicinal nicotine, 'nicotine tablet,' 'over-the-counter nicotine', 'OTC nicotine', 'nicotine orally,' 'nicotine intranasal,' 'nicotine polacrilex,' 'nicotine sprays', 'nicotine sublingual,' 'nicotine lozenges' and 'nicotine inhalers'. These keywords were used to search titles. Although people reported that using electronic cigarette (EC) may reduce cigarette smoking consumption and help quit smoking [42, 43], EC was not included as an avenue of nicotine replacement. Little evidence is known about EC, and relatively little research on this issue has been performed [44-46]. In a recent systematic review about EC that health care providers are recommended to be aware that EC devises are of unknown safety and of unsure help as an effective smoking-cessation strategy [47].

Most of the time, NRT term is used as a general term in many different types of sciences. So, to avoid this confusion, the following keywords: 'smoking' and 'tobacco' were entered as 'article title, abstract, keywords'. The bibliometric analysis is determined by looking at all past years up to December 31, 2016 and all citations analysis were accomplished on December 22, 2017 to avoid any updating on the database [14]. Research output in the years 2017 was expelled from further analysis. Furthermore, erratum documents were excluded from analysis.

The NRT research productivity was analyzed as previous similar bibliometric studies [2, 14, 24-27] by examining the relative growth rate, citations patterns, collaborative measures, the most prolific institutions and journals. The indicators of bibliometric evaluation including countries, journals, cited articles, and institutions were transformed to the rank order by using the standard competition ranking (SCR) (i.e. "1224" ranking) as in previous similar bibliometric studies [33, 34, 48-50]. Only the ten top-ranked of the measurements were taken into account. In addition, the impact factor (IF) for the ten top-ranked journals was derived from 2016 Journal Citation Reports (JCR). Furthermore, the h-index (also known as Hirsch index) was used as qualitative measure to assess the scientific research performance in the field of NRT for the ten top-ranked countries. The $h$-index was introduced by J. Hirsch in 2005 [51] and is defined as follows: "A certain country has an $h$-index, if it has at least $h$ publications for which it has received at least h citations".

\section{Statistical analysis}

All extracted data from Scopus were analyzed using Statistical Package for Social Sciences software (SPSS, version 15.0). Frequency, percentage, median, and interquartile range (IQR: i.e. Q1-Q3, lower quartile-upper quartile) were considered. Research activity for the top 10 countries were adjusted to the population size (publications per 1 million inhabitants) and the gross domestic product (GDP) value (publications per \$1 billion USD of GDP) 
retrieved from the online databases of the World Bank [52], and data associated with prevalence of tobacco smoking retrieved from the online databases of the World Health Organization [53]. Pearson's correlation coefficient test was used to assess the correlations between number of publications and the countries' population and economies indicators or prevalence of tobacco smoking. $P<$ 0.05 was considered significant. In addition, VOSviewer software version 1.6.6 [54] was used to build bibliometric diagrams for visualization the co-occurrence network of terms extracted from the title or abstract of the articles, and to visualize the collaboration network between countries.

\section{Results}

Using the methodology presented above, 2138 documents related to the use of NRT in tobacco cessation were retrieved. Among them, 1533 (71.7\%) were original journal articles, distantly followed by note (171, 8.0\%), letters to the editor $(160,7.5 \%)$, review articles (149, $7.0 \%)$, and other document types such as editorials (125, $4.8 \%$ ). The yearly production trend increased steadily from 1970 to 2016, and showed a clearer trend to increase in the last years (Fig. 1). The first article related to NRT for tobacco cessation in Scopus was published by Jarvik et al. in Clinical Pharmacology \& Therapeutics in 1970 [55]. Most documents published in the field of NRT were in English $(n=1961 ; 91.7 \%)$, followed by German $(n=55 ; 2.6 \%)$, French $(n=31 ; 1.4 \%)$ and Spanish language documents $(n=30 ; 1.4 \%)$.

The 2138 documents on NRT research were published by research groups in 56 countries/territories. Figure 2 shows the collaboration network of countries who had at least five publications. The thickness of lines indicates the size of collaboration and the size of circles signifies the number of publications of the country. In addition,

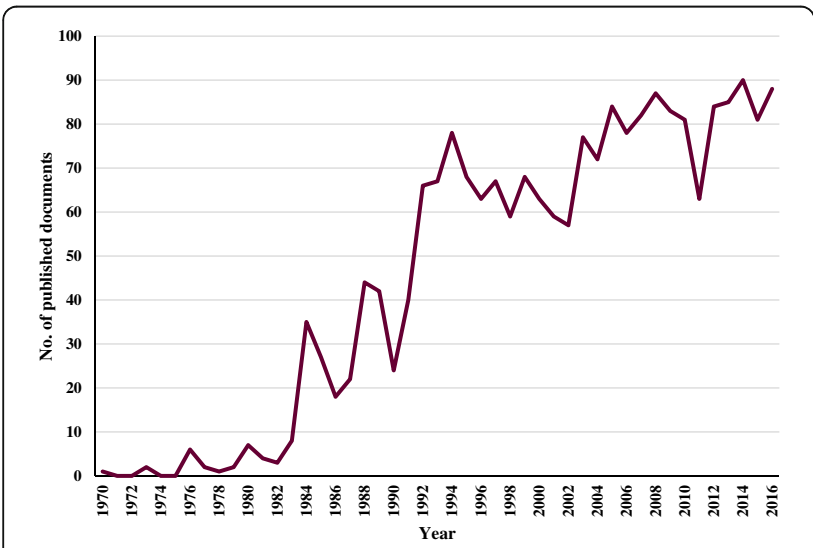

Fig. 1 The total articles included in a bibliometric analysis of worldwide publications related to nicotine replacement therapy for tobacco cessation from 1970 to 2015 the USA produces the most international collaborative documents, with involvement from 32 countries, followed by 21 countries for the UK and 19 for Sweden. The top 10 countries published 1809 documents, accounting for $84.6 \%$ of the total number of publications. The USA has the most number of published articles accounted to 986 , followed by the UK (312 publications) and then Australia (102 publications), and Sweden (102 publications); (Table 1). No data related to NRT were published from 156 (73.6\%). The publication tendency of the most active 4 countries among the first 10 countries in the field of NRT was revealed in Fig. 3. After adjusting for population size, Sweden, New Zealand and Denmark become the most prolific country by achieving the highest number of publications per population size in million inhabitants (10.303, 7.249, and 7.155, respectively). Additionally, after adjusting for the socio-economic parameters, New Zealand, Denmark, and the UK become the most prolific country by achieving the highest number of publications per GDP (current US\$) in billion (0.184, 0.134 , and 0.118 , respectively); (Table 1 ). No significant correlation was found between the country population size or 2016 GDP values and the number of publications of the top-10 most prolific countries in the field of NRT $(r=-0.156, P=0.664$; and $r=-0.173, P=0.632$, respectively). Furthermore, there is no correlation between prevalence of tobacco smoking and number of publications of the top-10 most prolific countries in the field of NRT $(r=-0.235, P=0.514)$.

The total number of citations for the published articles related to the use of NRT in tobacco cessation was 57,333 , with a median of citations (interquartile range) nine (9-31) which achieved 26.8 citations per document. Moreover, the $h$-index for the published articles related to the use of NRT in tobacco cessation was 113 (113 articles had been achieved citations at least 113 times), and the highest $\mathrm{h}$ of an individual was 92 for the USA, followed by 57 for the UK.

The top 10 most productive journals are summarized in Table 2. Nicotine and Tobacco Research ranked first and published $143(6.69 \%)$ articles on NRT. Addiction published the second most articles (77, 3.60\%), followed by Psychopharmacology $(61,2.85 \%)$, and Addictive Behaviors $(54,2.53 \%)$. Furthermore, all the top 10 most productive journals had an official IF more than 2 . It was shown that the USA was the most prolific country for the top 10 most productive journals (Table 2). Medicine was the most researched area, achieved by 1760 $(82.3 \%)$ articles, followed by pharmacology, toxicology and pharmaceutics with 485 (22.7\%) articles, and psychology with 167 (7.8\%) articles.

The co-occurrence network of terms that extracted from the title or abstract of at least in 10 articles are presented in Fig. 4a. Overall, 445 of the 23,444 terms meet 


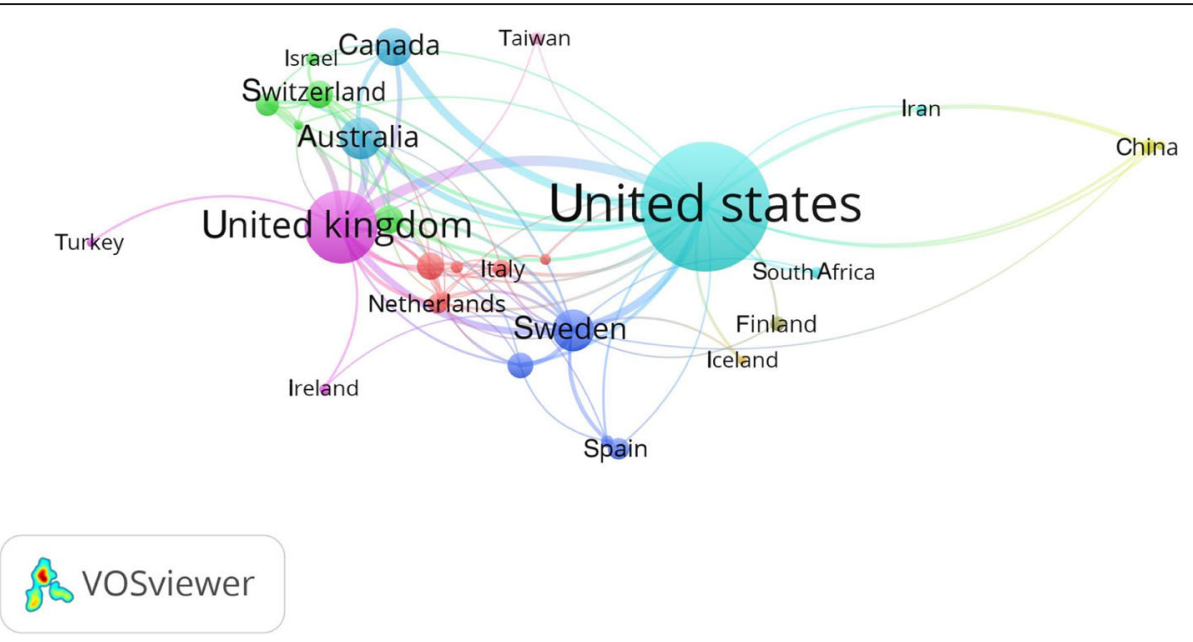

Fig. 2 Network visualization map of country co-authorships. Of the 56 countries, 35 had at least five publications; the largest set of connected countries consists of 35 countries in 10 clusters

the threshold of co-occurrence and the top $60 \%$ with the highest relevance, that is, 267 terms are set out in the figure and were classified into the 4 clusters according to different colors. The blue cluster mainly represents randomized clinical trials in which NRT in different dosage forms was compared to placebo. The yellow one include terms mainly grouping topics related to related to randomized clinical trials in which NRT in different dosage forms was compared vs. varenicline vs. bupropion vs. Combination. while the red cluster normally implement terms related to population survey studies regarding attitudes, practices, perceptions, and barriers in tobacco cessation. Moreover, the green cluster includes side effect of NRT and pharmacokinetic terms as well. Terms were color coded by VOSviewer based on the average time they founded in the 2138 related publications (Fig. 4b). Figure $3 \mathrm{~b}$ represented the earlier (blue color) or later (red color) years when the term appeared. Before 2010, in the early stage of NRT research, the main popular topics were related to clinical trials of NRT. The latest trends showed that the main popular topics were related to population survey studies regarding NRT.

Table 3 shows the articles with high citations from 1970 to 2016. Number of citations ranged from 1348 to

Table 1 The top 10 ranking of the most productive countries in publishing the largest number of articles associated with nicotine replacement therapy for tobacco cessation during the period from 1970 to 2016

\begin{tabular}{|c|c|c|c|c|c|c|c|c|c|}
\hline$\overline{S C R^{a}}$ & Countries & Articles (\%) & $h$-index & $\begin{array}{l}\text { Publications } \\
\text { per population } \\
\text { size in million } \\
\text { inhabitants }\end{array}$ & $\begin{array}{l}\text { Publications per } \\
\text { GDP (current US\$) } \\
\text { in billion }\end{array}$ & $\begin{array}{l}\text { Prevalence } \\
\text { of tobacco } \\
\text { smoking }^{b}\end{array}$ & $\begin{array}{l}\text { Number of } \\
\text { Publications per } \\
100,000 \text { smokers }\end{array}$ & $\begin{array}{l}\text { Collaborations } \\
\text { with foreign } \\
\text { countries }\end{array}$ & $\begin{array}{l}\text { Number }(\%)^{c} \text { of } \\
\text { documents with } \\
\text { international authors }\end{array}$ \\
\hline $1 s t$ & United States & $986(46.1)$ & 92 & 3.051 & 0.053 & 17.2 & 1.77 & 32 & $127(12.9)$ \\
\hline 2nd & United Kingdom & $312(14.6)$ & 57 & 4.753 & 0.118 & 19.2 & 2.48 & 21 & $98(31.4)$ \\
\hline $3 r d$ & Australia & $102(4.8)$ & 25 & 4.227 & 0.085 & 14.9 & 2.84 & 8 & $35(34.3)$ \\
\hline $3 r d$ & Sweden & $102(4.8)$ & 41 & 10.303 & 0.198 & 20.6 & 5.00 & 19 & $56(54.9)$ \\
\hline 5 th & Canada & $85(4.0)$ & 23 & 2.342 & 0.056 & 14.9 & 1.57 & 6 & $33(38.8)$ \\
\hline 6th & France & $51(2.4)$ & 16 & 0.762 & 0.021 & 27.6 & 0.28 & 11 & $12(23.5)$ \\
\hline 7 th & Germany & $49(2.3)$ & 13 & 0.593 & 0.014 & 30.3 & 0.20 & 11 & $14(28.6)$ \\
\hline 8th & Switzerland & $47(2.2)$ & 21 & 5.615 & 0.070 & 23.2 & 2.42 & 9 & $17(36.2)$ \\
\hline 9th & Denmark & $41(1.9)$ & 22 & 7.155 & 0.134 & 17.0 & 4.21 & 8 & $12(29.3)$ \\
\hline 10th & New Zealand & 34 (1.6) & 15 & 7.249 & 0.184 & 16.3 & 4.45 & 6 & $18(52.9)$ \\
\hline
\end{tabular}

SCR Standard Competition Ranking

${ }^{a}$ Equal countries have the same ranking number, and then a gap is left in the ranking numbers

${ }^{\mathrm{b}}$ Age-standardized prevalence of current tobacco smoking among people aged 15 years and older [53]

${ }^{c}$ Percentage of documents with international authors from the total number of documents for each country 


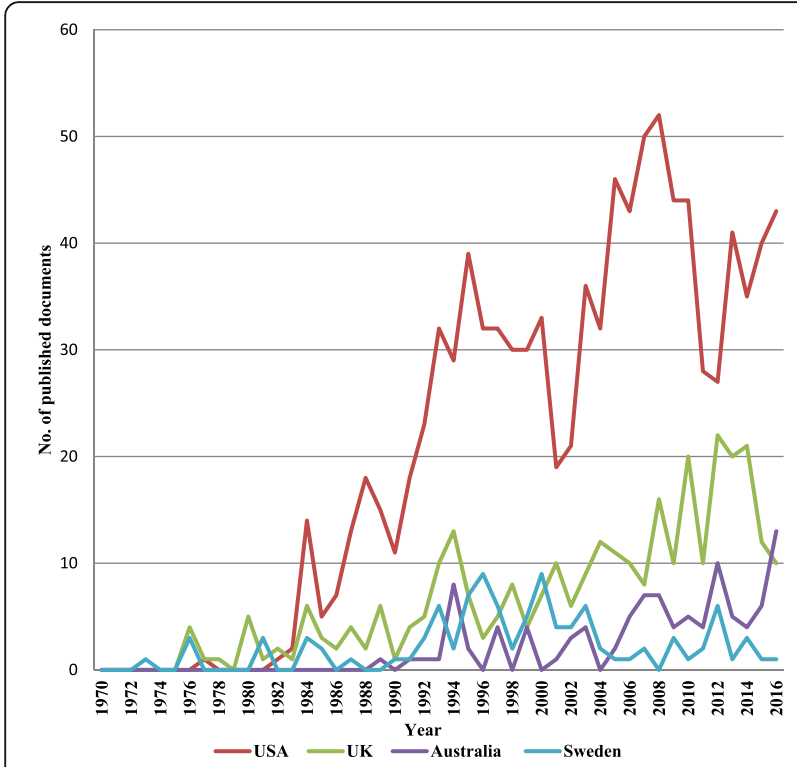

Fig. 3 Annual number of publications for top 4 productive countries during 1970-2015

325 [6, 39, 56-63]. Table 4 illustrates the top 10 prolific institutions ranked by the numbers of publications. The most productive institution was the VA Medical Center, USA (3.18\%), followed by King's College London, UK (3.13\%), and University of Pittsburgh, USA (3.04\%). For authors who had the most publications in the field of NRT (Table 5), Shiffman, S ranked the first (59 publications), followed by Benowitz, NL (54 publications), and West, R (53 publications). The cooperation between authors was elucidated in a network map (Fig. 5).

\section{Discussion}

Reducing morbidity and mortality associated with tobacco use involves an understanding of how scientific research related to tobacco use has progressed. Such study is helpful in implementation or developing of an efficient strategies to respond to this progress [25, 64]. To my knowledge, this is a first study that using bibliometric approach analysis to estimate the NRT literature indexed in Scopus database at global level. Bibliometric indicators in the current study illustrated that research output in the field of NRT was ignored in most countries. The current study also adds to the emerging international bibliometric studies in the field of tobacco smoking $[2,14,16-20]$, which may open doors to new research on the evaluation of effective smokingcessation strategies and counselling services.

However, the first publications related to NRT were introduced in the early 1970s, the Lancet was published in 1942 paper entitled 'Tobacco smoking and nicotine' by Johnston who recognised smoking as one of the most important factors for lung cancer and later he considered one of the first anti-smoking campaigners by suggesting a total ban on smoking [65]. Johnston reported that he had administered a subcutaneous small dose of nicotine solution to 35 volunteers, including himself [65]. He declared that if nicotine injections were abruptly discontinued, craving to tobacco will be arise. He demonstrated that smoking tobacco (i.e. smoking

Table 2 The top10 ranking of journals in which articles associated with nicotine replacement therapy for tobacco cessation were published worldwide

\begin{tabular}{|c|c|c|c|c|c|}
\hline $\mathrm{SCR}^{a}$ & Journal & country of journal's origin & Frequency (\%) & $\mathrm{IF}^{\mathrm{b}}$ & $\begin{array}{l}\text { Most productive country } \\
\text { (No. of documents-\%) }\end{array}$ \\
\hline $1 \mathrm{st}$ & Nicotine and Tobacco Research & UK & $143(6.69)$ & 4.609 & USA (99-69.2) \\
\hline 2nd & Addiction & UK & $77(3.60)$ & 5.789 & USA (34-44.2) \\
\hline $3 r d$ & Psychopharmacology & Germany & $61(2.85)$ & 3.308 & USA (34-55.7) \\
\hline 4 th & Addictive Behaviors & UK & $54(2.53)$ & 2.944 & USA (36-66.7) \\
\hline 4 th & Tobacco Control & UK & $54(2.53)$ & 5.469 & USA (35-64.8) \\
\hline 6th & British Medical Journal & UK & $37(1.73)$ & 20.785 & UK (31-83.8) \\
\hline 7th & $\begin{array}{l}\text { JAMA - Journal of the American } \\
\text { Medical Association }\end{array}$ & USA & $33(1.54)$ & 44.405 & USA (29-87.9) \\
\hline 8th & Drug and Alcohol Dependence & Netherlands & $28(1.31)$ & 3.222 & USA (23-82.1) \\
\hline 9th & Annals of Internal Medicine & USA & $27(1.26)$ & 17.135 & USA (18-66.7) \\
\hline 10th & $\begin{array}{l}\text { Journal of Consulting and Clinical } \\
\text { Psychology }\end{array}$ & USA & $25(1.17)$ & 4.593 & USA (24-96.0) \\
\hline 10th & Preventive Medicine & USA & $25(1.17)$ & 3.434 & USA(18-72.0) \\
\hline
\end{tabular}

SCR Standard Competition Ranking, IF impact factor

${ }^{a}$ Equal journals have the same ranking number, and then a gap is left in the ranking numbers

${ }^{\mathrm{b}}$ The impact factor was reported according to Institute for Scientific Information (ISI) journal citation reports (JCR) 2016 

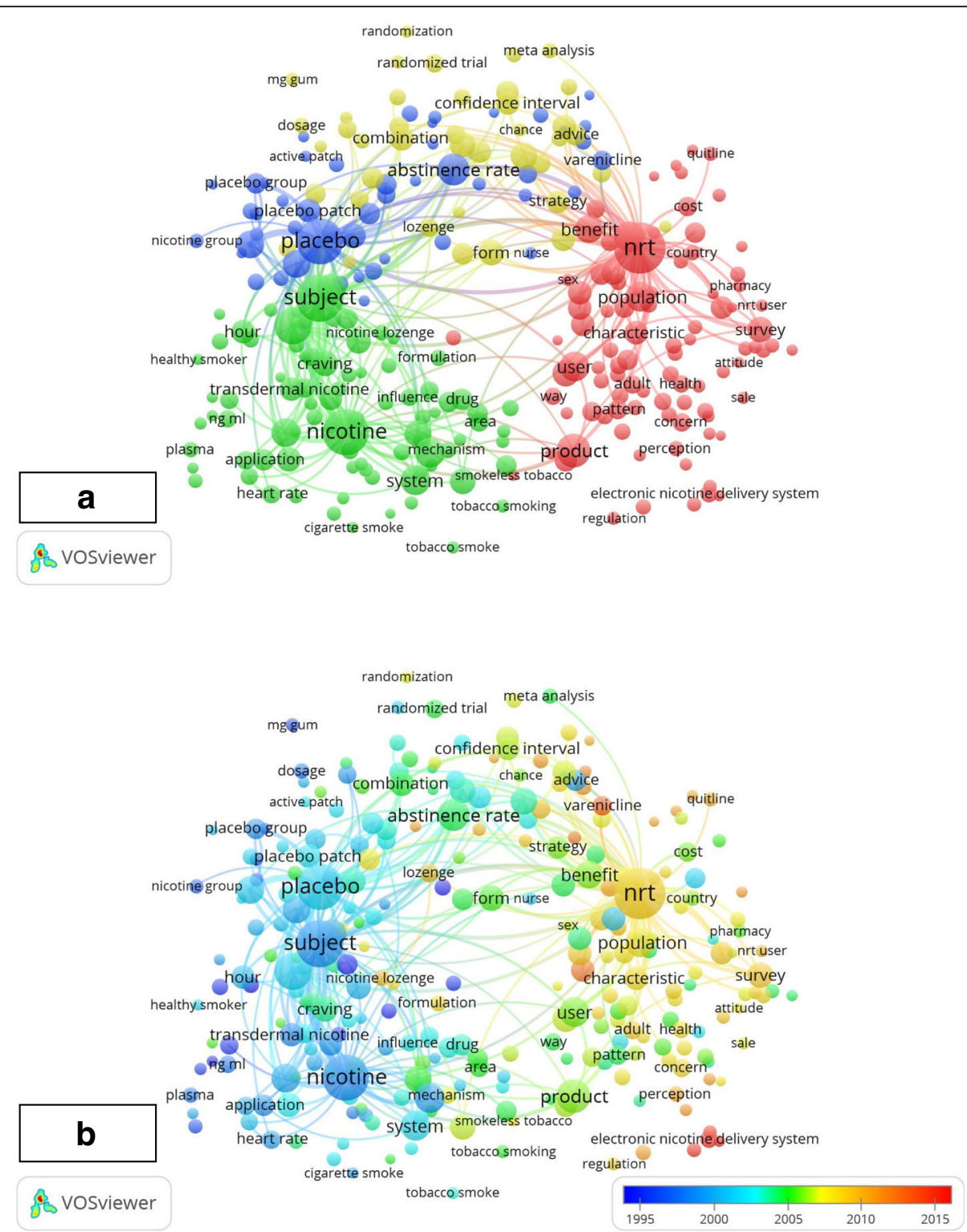

Fig. 4 Mapping of terms in the research on nicotine replacement therapy (NRT). a shows the co-occurrence network of terms that extracted from the title or abstract of at least 10 articles. Colors represent groups of terms that are relatively strongly linked to each other. The size of a term signifies the number of publications related to NRT in which the term was appeared, and the distance between two terms represents an estimated indication of the relatedness of these terms. $\mathbf{b}$ represents the earlier (blue color) or later (red color) years when the term appeared

addiction) is actually a means of administer nicotine, similar to smoking opium is essentially a means to administer morphine $[65,66]$. Jarvik and colleagues published the first article about the use of orally administered nicotine for tobacco substitutes in 1970 in Clinical Pharmacology \& Therapeutics. Jarvik et al. found that nicotine administration produces a significant decrease in the average number of cigarettes smoked [55]. Later, Jarvik became the co-inventor of the nicotine patch. Three years later, Ferno and colleagues developed a chewing nicotine gum that released nicotine at a suitable rate when chewed [67]. A preliminary report given at the Second World Conference on Smoking and Health in 1971 in London compared the nicotine-containing chewing gum with a placebo gum in a double blind study [68], and the results were published in 1973 in Psychopharmacologia [69].

The USA was the most prolific country, accounting for $46.1 \%(n=986)$ of total output. Furthermore, the USA was the most collaborative country in the world and got the central position in the collaborative network. This finding was similar to other recent studies related to waterpipe tobacco smoking and EC [14, 28]. The current research indicates that Australia has published 
Table 3 The top 10 ranking of cited articles worldwide associated with the use of nicotine replacement therapy for tobacco cessation in Scopus

\begin{tabular}{|c|c|c|c|c|}
\hline$\overline{S C R^{a}}$ & $\begin{array}{l}\text { Authors with year } \\
\text { of publication }\end{array}$ & Title & Source title & Cited by \\
\hline $1 s t$ & Jorenby et al., [59] & $\begin{array}{l}\text { "A controlled trial of sustained-release bupropion, } \\
\text { a nicotine patch, or both for smoking cessation" }\end{array}$ & New England Journal of Medicine & 1348 \\
\hline 2nd & Fiore et al., [58] & $\begin{array}{l}\text { "The effectiveness of the nicotine patch for smoking } \\
\text { cessation: A meta-analysis" }\end{array}$ & Journal of the American Medical Association & 547 \\
\hline $3 r d$ & Stead et al., [6] & "Nicotine replacement therapy for smoking cessation" & Cochrane Database of Systematic Reviews & 536 \\
\hline 4th & Silagy et al., [63] & $\begin{array}{l}\text { "Meta-analysis on efficacy of nicotine replacement } \\
\text { therapies in smoking cessation" }\end{array}$ & Lancet & 400 \\
\hline 5 th & Benowitz and Gourlay, [56] & $\begin{array}{l}\text { "Cardiovascular toxicity of nicotine: Implications for } \\
\text { nicotine replacement therapy" }\end{array}$ & Journal of the American College of Cardiology & 381 \\
\hline 5 th & Pullan et al., [62] & "Transdermal nicotine for active ulcerative colitis" & New England Journal of Medicine & 381 \\
\hline 7th & Joseph et al., [60] & $\begin{array}{l}\text { "The safety of transdermal nicotine as an aid to } \\
\text { smoking cessation in patients with cardiac disease" }\end{array}$ & New England Journal of Medicine & 379 \\
\hline 8th & Benowitz et al., [57] & $\begin{array}{l}\text { "Nicotine absorption and cardiovascular effects with } \\
\text { smokeless tobacco use: Comparison with cigarettes } \\
\text { and nicotine gum" }\end{array}$ & Clinical Pharmacology and Therapeutics & 371 \\
\hline 9th & Kenford et al., [61] & $\begin{array}{l}\text { "Predicting smoking cessation: Who will quit with } \\
\text { and without the nicotine patch" }\end{array}$ & Journal of the American Medical Association & 334 \\
\hline 10th & Stead et al. [39] & "Nicotine replacement therapy for smoking cessation" & Cochrane Database of Systematic Reviews & 325 \\
\hline
\end{tabular}

SCR Standard Competition Ranking

${ }^{a}$ Equal articles have the same ranking number, and then a gap is left in the ranking numbers

the greatest number of research articles from the AsiaPacific region, while Sweden has published the majority of research articles from Europe. The 10 most prolific countries to publish articles on NRT consist of numerous nations that will be similar to other scientific output rankings [70]. This research output from these countries is possible due to fact that these are: a) countries with more resources [71], b) countries experiencing high rates of tobacco smoking [53], c) countries with a research and publishing culture in relation to tobacco smoking [72-75], and d) countries that publish most journals in

Table 4 Top 10 ranking of highly productive institutions that most frequently published articles associated with the use of NRT in tobacco cessation worldwide

\begin{tabular}{lll}
\hline SCR $^{\text {a }}$ & Institutions & No. of documents (\%) \\
\hline 1st & VA Medical Center, USA & $68(3.18)$ \\
2nd & King's College London, UK & $67(3.13)$ \\
3rd & University of Pittsburgh, USA & $65(3.04)$ \\
4th & University of California, San Francisco, USA & $58(2.71)$ \\
4th & University of Minnesota Twin Cities, USA & $58(2.71)$ \\
6th & University College London, UK & $54(2.53)$ \\
7th & Mayo Clinic, USA & $51(2.39)$ \\
7th & Pinney Associates, USA & $51(2.39)$ \\
9th & University of Vermont, USA & $42(1.96)$ \\
10th & University of Nottingham, UK & $41(1.92)$ \\
\hline
\end{tabular}

SCR Standard Competition Ranking

${ }^{a}$ Equal institutions have the same ranking number, and then a gap is left in the ranking numbers the field of health [76]. In the current study, the performance in research output for every country is different. This study demonstrated that the USA and the UK are the most influential countries in the field of NRT. This activity may be associated with the population size, and socioeconomic of these countries [77]. No study has been found in the literature similar to this point, thus the author was interpreting these results in light of other results. These findings are consistent with data obtained in other previous research which found similar findings [78, 79]. Countries with fast-rising economies, which consequently have more funding and investment for conducting research [25], thus may contribute to increasing number of publications regarding NRT.

In this study, the average citation rate was 26.8 citations per article. This citation was higher than the average citation of papers published in toxicological journals [24, 26, 80-82]. A more recent studies using similar bibliometric indicators found the average citation rate for waterpipe tobacco smoking publications was 13 citations per article, and for EC publications was 6.4 citations per article $[14,28]$. This finding indicates that NRT become a hot issue in scientific research.

Another important finding was that was the investigation of publications' quality. To note, all the top 10 journals in which international articles related to NRT were published carried IFs greater than 2.00 and had significant impact in the field of tobacco smoking. Articles from Sweden amassed high $h$-index. This achievement is due to the fact that Sweden developed the first effective 
Table 5 Top ten prolific authors who published the most frequently articles associated with the use of NRT in tobacco cessation worldwide

\begin{tabular}{|c|c|c|c|}
\hline$S C R^{a}$ & Author & No. of documents (\%) & Affiliation \\
\hline $1 s t$ & Shiffman, S. & $59(2.76)$ & University of Pittsburgh, Pittsburgh, PA, USA. \\
\hline 2nd & Benowitz, N.L. & $54(2.53)$ & University of California, San Francisco, CA, USA \\
\hline $3 r d$ & West, R. & $53(2.48)$ & University College London, London, UK \\
\hline 4 th & Hatsukami, D.K. & $46(2.15)$ & $\begin{array}{l}\text { University of Minnesota, Twin Cities. Minneapolis, MN, } \\
\text { United States. }\end{array}$ \\
\hline 5 th & Hughes, J.R. & $44(2.06)$ & University of Vermont, Burlington, VT 05401, USA \\
\hline 6th & Hurt, R.D. & $40(1.87)$ & Mayo Clinic, Rochester, MN, USA \\
\hline 7th & Croghan, I.T. & $34(1.59)$ & Mayo Clinic, Rochester, MN, USA \\
\hline 8th & Tønnesen, P. & $30(1.40)$ & Glostrup Hospital, Glostrup, Denmark \\
\hline 9th & Lerman, C. & $28(1.31)$ & University of Pennsylvania, Philadelphia, PA, USA \\
\hline 10th & Coleman, $\mathrm{T}$. & $26(1.22)$ & $\begin{array}{l}\text { University of Nottingham Medical School, Queen's Medica } \\
\text { Centre, Nottingham, UK }\end{array}$ \\
\hline 10th & Cummings, K.M. & $26(1.22)$ & $\begin{array}{l}\text { Medical University of South Carolina, } 67 \text { President Street, } \\
\text { Charleston, SC 29425, USA }\end{array}$ \\
\hline
\end{tabular}

SCR Standard Competition Ranking

${ }^{a}$ Equal authors have the same ranking number, and then a gap is left in the ranking numbers

therapies for tobacco dependence. Nicotine chewing gum (i.e. Nicorette) was the first therapeutic preparation aiding in smoking cessation which was developed by Ove Fernö at Leo pharmaceutical company in Sweden and was first approved in Switzerland in 1978 [83], following an idea from Fernö's colleagues, Stefan Lichtneckert and Claes Lundgren, at the Physiological Institute of Lund University in Sweden in 1967 [67, 83].
It is necessary to take into account a number of limitations as in other previous bibliometric studies [31, 32, 34, 49, 50, 84, 85]. First, the Scopus database was used to search for NRT studies. Thus, the contribution of nonScopus-publication may have been underestimated. Second, the chosen key words might not be comprehensive. Therefore, false negative results are a possibility. Third, some articles did not contain NRT and related

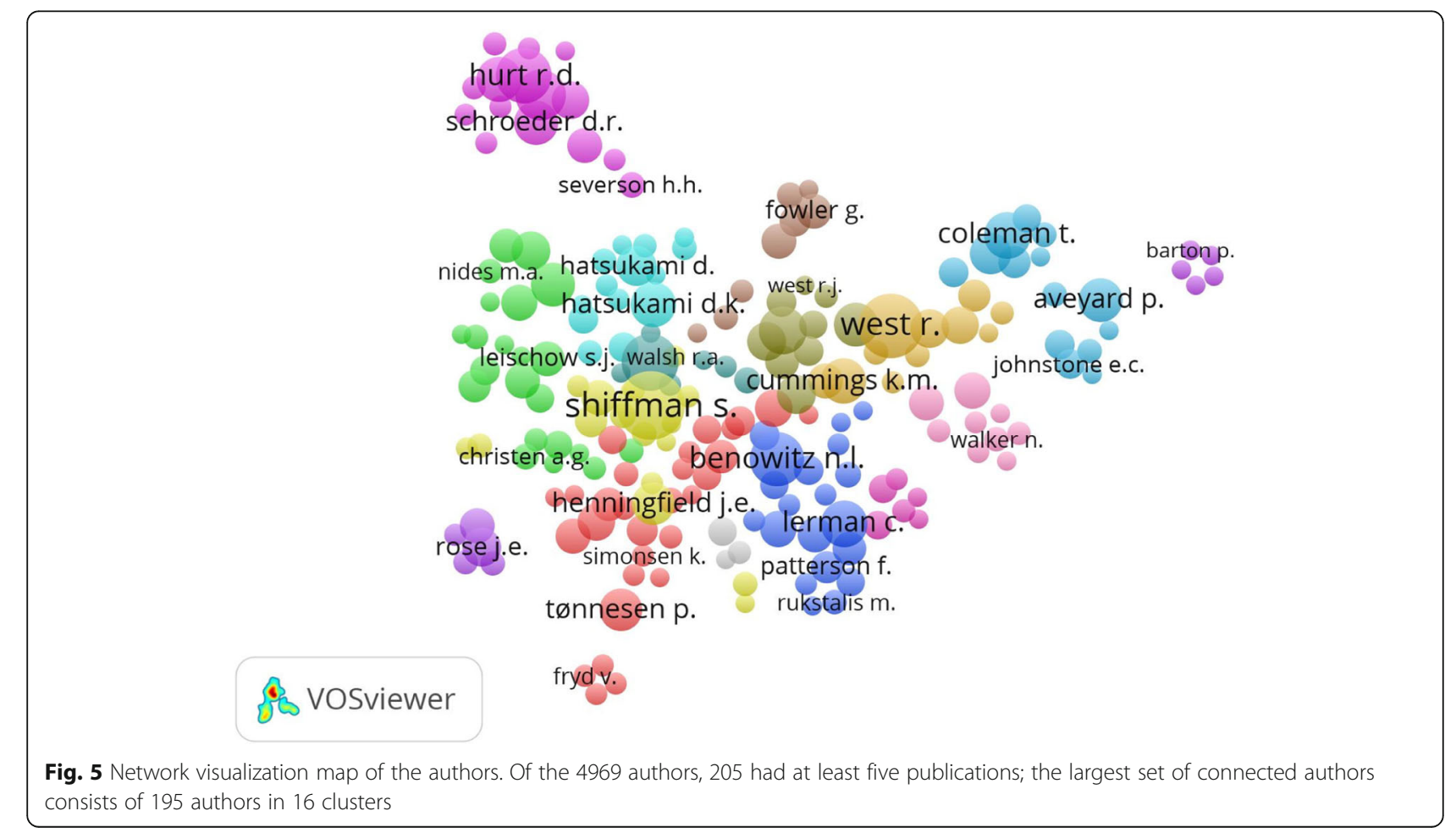


keywords in the publication titles. Therefore, NRT and related keywords were mentioned inside the text or abstract were not included in this study. Another limitation that this bibliometric analysis results in a significant bias in the sense that the researcher has little or no control over the key problems associated with a lack of production of studies related to NRT.

\section{Conclusions}

The present data reveal a solid mass of research activity on NRT. The USA attained a leading position in global NRT research, with the largest number of independent and international collaborative publications. NRT-based research activities were low or not available in most countries. As NRT research has been thought to be generally useful to humans, more efforts should be taken to further research in this field. The current study provides useful information to researchers and funding societies concerned in the implementation of research strategies to improve NRT research for small economies or to address global health issues related to tobacco control services. Furthermore, the findings of this study demonstrate that use of NRT in tobacco cessation remains a hot issue in scientific research. Moreover, side effects, pharmacokinetic aspects of NRT, survey population studies, and clinical trials have been recognized as the most prominent hotspots in the research related to NRT. Additionally, The results of this study delineate a framework for better understanding the situations of current NRT research and prospective directions of the research in this field which could be applied for managing and prioritizing future research efforts in NRT research.

\section{Abbreviations}

GDP: Gross domestic product; IFs: Impact factors; IQR: Interquartile range; ISI: Institute for Scientific Information; JCR: Journal citation report; NRT: Nicotine replacement therapy; SPSS: Statistical package for social sciences; WHO FCTC: World Health Organization Framework Convention on Tobacco Control

\section{Acknowledgements}

Not applicable.

\section{Author's contribution}

SZ wrote this article and takes full responsibility. The author read and approved the final manuscript.

\section{Funding}

No funding was received for this work.

\section{Availability of data and materials}

The Scopus database was used for the present study.

\section{Ethics approval and consent to participate}

Not applicable.

\section{Consent for publication}

Not applicable.

\section{Competing interests}

The author declares that he has no competing interest.

\section{Publisher's Note}

Springer Nature remains neutral with regard to jurisdictional claims in published maps and institutional affiliations.

Received: 25 August 2015 Accepted: 18 January 2018

Published online: 30 January 2018

\section{References}

1. World Health Organization. WHO report on the global tobacco epidemic, 2011: warning about the dangers of tobacco. Geneva: World Health Organization; 2011. http://whalibdoc.who.int/publications/2011/ 9789240687813_eng.pdf. Accessed 23 Sept 2013

2. Zyoud SH, Al-Jabi SW, Sweileh WM, Awang R. A Scopus-based examination of tobacco use publications in Middle Eastern Arab countries during the period 2003-2012. Harm Reduct J. 2014;11:14.

3. World Health Organization (WHO). WHO framework convention on tobacco control. Geneva, Switzerland. 2003. http://whalibdoc.who.int/publications/ 2003/9241591013.pdf. Accessed 11 Oct 2013.

4. Wu P, Wilson K, Dimoulas P, Mills EJ. Effectiveness of smoking cessation therapies: a systematic review and meta-analysis. BMC Public Health. 2006;6:300.

5. Kralikova E, Kozak JT, Rasmussen T, Gustavsson G, Le Houezec J. Smoking cessation or reduction with nicotine replacement therapy: a placebocontrolled double blind trial with nicotine gum and inhaler. BMC Public Health. 2009:9:433.

6. Stead LF, Perera R, Bullen C, Mant D, Hartmann-Boyce J, Cahill K, et al. Nicotine replacement therapy for smoking cessation. Cochrane Database Syst Rev. 2012;11:Cd000146.

7. Foulds J, Steinberg MB, Williams JM, Ziedonis DM. Developments in pharmacotherapy for tobacco dependence: past, present and future. Drug Alcohol Rev. 2006:25(1):59-71.

8. Gomez-Coronado N, Walker AJ, Berk M, Dodd S. Current and emerging pharmacotherapies for cessation of tobacco smoking. Pharmacotherapy. 2017; https://doi.org/10.1002/phar.2073. [Epub ahead of print].

9. Hsia SL, Myers MG, Chen TC. Combination nicotine replacement therapy: strategies for initiation and tapering. Prev Med. 2017;97:45-9.

10. Prochaska JJ. Nicotine replacement therapy as a maintenance treatment. JAMA. 2015;314(7):718-9.

11. Smith SS, Keller PA, Kobinsky KH, Baker TB, Fraser DL, Bush T, et al. Enhancing tobacco quitline effectiveness: identifying a superior pharmacotherapy adjuvant. Nicotine Tob Res. 2013;15(3):718-28.

12. Zhang B, Cohen JE, Bondy SJ, Selby P. Duration of nicotine replacement therapy use and smoking cessation: a population-based longitudinal study. Am J Epidemiol. 2015;181(7):513-20.

13. de Granda-Orive Jl, Villanueva-Serrano S, Aleixandre-Benavent R, ValderramaZurian JC, Alonso-Arroyo A, Garcia Rio F, et al. Network of international scientific collaboration on smoking: analysis of coauthorship through the science citation index (1999-2003). Gac Sanit. 2009;23(3):222. e34-43

14. Zyoud SH, Al-Jabi SW, Sweileh WM. Bibliometric analysis of scientific publications on waterpipe (narghile, shisha, hookah) tobacco smoking during the period 2003-2012. Tob Induc Dis. 2014;12(1):7.

15. Wiysonge CS, Uthman OA, Ndumbe PM, Hussey GD. A bibliometric analysis of childhood immunization research productivity in Africa since the onset of the expanded program on immunization in 1974. BMC Med. 2013;11:66.

16. Garcia-Lopez JA. Bibliometric analysis of Spanish scientific publications on tobacco use during the period 1970-1996. Eur J Epidemiol. 1999;15(1):23-8.

17. Cohen JE, Chaiton MO, Planinac LC. Taking stock a bibliometric analysis of the focus of tobacco research from the 1980s to the 2000s. Am J Prev Med. 2010;39(4):352-6.

18. Warner KE, Tam J, Koltun SM. Growth in tobacco control publications by authors from low- and middle-income countries. Tob Control. 2014;23(3):231-7.

19. Kira A, Glover M, Bullen C, Viehbeck S. Publications as an indicator of increased tobacco control research productivity (quantity and quality) in New Zealand. Nicotine Tob Res. 2011;13(6):474-8.

20. Nykiforuk $\mathrm{Cl}$, Osler $\mathrm{GE}$, Viehbeck $\mathrm{S}$. The evolution of smoke-free spaces policy literature: a bibliometric analysis. Health Policy. 2010;97(1):1-7.

21. Wallin JA. Bibliometric methods: pitfalls and possibilities. Basic Clin Pharmacol Toxicol. 2005;97(5):261-75.

22. Tan J, Fu H-Z, Ho Y-S. A bibliometric analysis of research on proteomics in science citation index expanded. Scientometrics. 2013;98(2):1473-90.

23. Smith DR. Impact factors, scientometrics and the history of citation-based research. Scientometrics. 2012;92(2):419-27. 
24. Zyoud SH, Al-Jabi SW, Sweileh WM. Worldwide research productivity of paracetamol (acetaminophen) poisoning: a bibliometric analysis (20032012). Hum Exp Toxicol. 2015;34(1):12-23.

25. Zyoud SH, Al-Jabi SW, Sweileh WM, Awang R. A bibliometric analysis of toxicology research productivity in Middle Eastern Arab countries during a 10-year period (2003-2012). Health Res Policy Syst. 2014;12(1):4.

26. Zyoud S, Al-Jabi S, Sweileh W, Awang R. A bibliometric analysis of research productivity of Malaysian publications in leading toxicology journals during a 10-year period (2003-2012). Hum Exp Toxicol. 2014;33(12):1284-93.

27. Sweileh WM, Zyoud SH, Al-Jabi SW, Sawalha AF. Assessing urology and nephrology research activity in Arab countries using ISI web of science bibliometric database. BMC Res Notes. 2014;7:258.

28. Zyoud SH, Al-Jabi SW, Sweileh WM. Worldwide research productivity in the field of electronic cigarette: a bibliometric analysis. BMC Public Health. 2014;14:667.

29. Palomo J, Figueroa-Domeca C, Laguna P. Women, peace and security stateof-art: a bibliometric analysis in social sciences based on SCOPUS database. Scientometrics. 2017;113(1):123-48.

30. Wei M, Wang W, Zhuang Y. Worldwide research productivity in the field of spine surgery: a 10-year bibliometric analysis. Eur Spine J. 2016;25(4):976-82.

31. Al-Jabi SW. Global research trends in West Nile virus from 1943 to 2016: a bibliometric analysis. Glob Health. 2017;13(1):55.

32. Al-Jabi SW. Global trends in aspirin resistance-related research from 1990 to 2015: a bibliometric analysis. Basic Clin Pharmacol Toxicol. 2017;121(6):512-9.

33. Zyoud SH. Global toxocariasis research trends from 1932 to 2015: a bibliometric analysis. Health Res Policy Syst. 2017;15(1):14.

34. Zyoud SH, Waring WS, Sweileh WM, Al-Jabi SW. Global research trends in lithium toxicity from 1913 to 2015: a bibliometric analysis. Basic Clin Pharmacol Toxicol. 2017;121(1):67-73.

35. Amodei N, Lamb RJ. Over-the-counter nicotine replacement therapy: can its impact on smoking cessation be enhanced? Psychol Addict Behav. 2008; 22(4):472-85.

36. Mendelsohn C. Optimising nicotine replacement therapy in clinical practice. Aust Fam Physician. 2013;42(5):305-9.

37. Moore D, Aveyard P, Connock M, Wang D, Fry-Smith A, Barton P. Effectiveness and safety of nicotine replacement therapy assisted reduction to stop smoking: systematic review and meta-analysis. BMJ. 2009;338:b1024.

38. Silagy C, Lancaster T, Stead L, Mant D, Fowler G. Nicotine replacement therapy for smoking cessation. Cochrane Database Syst Rev. 2004;3:CD000146.

39. Stead LF, Perera R, Bullen C, Mant D, Lancaster T. Nicotine replacement therapy for smoking cessation. Cochrane Database Syst Rev. 2008;Cd000146.

40. Thomas S. Smoking cessation. Part 2: nicotine replacement therapy. Nurs Stand. 2007;22(5):44-7.

41. Walsh RA. Over-the-counter nicotine replacement therapy: a methodological review of the evidence supporting its effectiveness. Drug Alcohol Rev. 2008;27(5):529-47.

42. Polosa R, Caponnetto P, Morjaria JB, Papale G, Campagna D, Russo C. Effect of an electronic nicotine delivery device (e-cigarette) on smoking reduction and cessation: a prospective 6-month pilot study. BMC Public Health. 2011;11:786

43. Farsalinos KE, Stimson GV. Is there any legal and scientific basis for classifying electronic cigarettes as medications? Int J Drug Policy. 2014;25(3):340-5.

44. Zyoud SH, Al-Jabi SW, Sweileh WM, Awang R. Assessing the scientific research productivity of a leading toxicology journal: a case study of Human \& Experimental Toxicology from 2003 to 2012. SAGE Open Med. 2014;2(0): 2050312114523424.

45. Paradise J. No sisyphean task: how the FDA can regulate electronic cigarettes. Yale J Health Policy Law Ethics. 2013;13(2):326-74.

46. Saitta D, Ferro GA, Polosa R. Achieving appropriate regulations for electronic cigarettes. Ther Adv Chronic Dis. 2014;5(2):50-61.

47. Harrell PT, Simmons VN, Correa JB, Padhya TA, Brandon TH. Electronic nicotine delivery systems ("e-cigarettes"): review of safety and smoking cessation efficacy. Otolaryngol Head Neck Surg. 2014;151(3):381-93.

48. Zyoud SH. Global research trends of Middle East respiratory syndrome coronavirus: a bibliometric analysis. BMC Infect Dis. 2016;16:255.

49. Zyoud SH, Waring WS, Al-Jabi SW, Sweileh WM. Global cocaine intoxication research trends during 1975-2015: a bibliometric analysis of web of science publications. Subst Abuse Treat Prev Policy. 2017;12(1):6.

50. Zyoud SH, Waring WS, Al-Jabi SW, Sweileh WM. Global research production in glyphosate intoxication from 1978 to 2015: a bibliometric analysis. Hum Exp Toxicol. 2017;36(10):997-1006.

51. Hirsch JE. An index to quantify an individual's scientific research output. Proc Natl Acad Sci U S A. 2005;102(46):16569-72
52. World Bank Group. Countries and economies 2016. 2017. https://data. worldbank.org/country. Accessed 26 Dec 2017.

53. World Health Organization. Prevalence of tobacco smoking. 2016. http:// apps.who.int/gho/data/node.sdg.3-a-viz?lang=en. Accessed 25 Dec 2017.

54. van Eck NJ, Waltman L. Software survey: VOSviewer, a computer program for bibliometric mapping. Scientometrics. 2010;84(2):523-38.

55. Jarvik ME, Glick SD, Nakamura RK. Inhibition of cigarette smoking by orally administered nicotine. Clin Pharmacol Ther. 1970;11(4):574-6.

56. Benowitz NL, Gourlay SG. Cardiovascular toxicity of nicotine: implications for nicotine replacement therapy. J Am Coll Cardiol. 1997;29(7):1422-31.

57. Benowitz NL, Porchet $\mathrm{H}$, Sheiner $\mathrm{L}$, Jacob $\mathrm{P}$ 3rd. Nicotine absorption and cardiovascular effects with smokeless tobacco use: comparison with cigarettes and nicotine gum. Clin Pharmacol Ther. 1988;44(1):23-8.

58. Fiore MC, Smith SS, Jorenby DE, Baker TB. The effectiveness of the nicotine patch for smoking cessation. A meta-analysis. JAMA. 1994;271(24):1940-7.

59. Jorenby DE, Leischow SJ, Nides MA, Rennard SI, Johnston JA, Hughes AR, et al. A controlled trial of sustained-release bupropion, a nicotine patch, or both for smoking cessation. N Engl J Med. 1999;340(9):685-91.

60. Joseph AM, Norman SM, Ferry LH, Prochazka AV, Westman EC, Steele BG, et al. The safety of transdermal nicotine as an aid to smoking cessation in patients with cardiac disease. N Engl J Med. 1996;335(24):1792-8.

61. Kenford SL, Fiore MC, Jorenby DE, Smith SS, Wetter D, Baker TB. Predicting smoking cessation. Who will quit with and without the nicotine patch. JAMA. 1994;271(8):589-94.

62. Pullan RD, Rhodes J, Ganesh S, Mani V, Morris JS, Williams GT, et al. Transdermal nicotine for active ulcerative colitis. N Engl J Med. 1994;330(12):811-5.

63. Silagy C, Mant D, Fowler G, Lodge M. Meta-analysis on efficacy of nicotine replacement therapies in smoking cessation. Lancet. 1994;343(8890):139-42.

64. Maziak W, Nakkash R, Bahelah R, Husseini A, Fanous N, Eissenberg T. Tobacco in the Arab world: old and new epidemics amidst policy paralysis. Health Policy Plan. 2014;29(6):784-94.

65. Johnston L. Tobacco smoking and nicotine. Lancet. 1942;2(742):743.

66. Brecher EM. Licit and illicit drugs. Boston: Little, Brown; 1972.

67. Fernö O, Lichtneckert SJA, Lundgren CEG. A substitute for tobacco smoking. Psychopharmacologia. 1973;31(3):201-4.

68. Ohlin $\mathrm{P}$, Westling $\mathrm{H}$, editors. Nicotine containing chewing gum as a substitute for smoking. Pitman: Proceedings of the Second World Conference on Smoking and Health; 1972.

69. Brantmark B, Ohlin P, Westling H. Nicotine-containing chewing gum as an anti-smoking aid. Psychopharmacologia. 1973;31(3):191-200.

70. Essential Science Indicators. Top 20 countries in ALL FIELDS, 2001-august 31 2011. 2012. http://archive.sciencewatch.com/dr/cou/2011/11decALL/. Accessed 20 Sept 2013.

71. Adams J, Griliches Z. Measuring science: an exploration. Proc Natl Acad Sci U S A. 1996:93(23):12664-70.

72. Durmuşoğlu ZDU, Çiftçi PK. An analysis of trends in publications on 'tobacco control'. Health Educ J. 2017:76(5):544-56.

73. Cohen JE, Chaiton MO, Planinac LC. Tobacco control and the epidemiological framework. Tob Control. 2011;20(4):318.

74. Groneberg DA, Weber E, Gerber A, Fischer A, Klingelhoefer D, Brueggmann D. Density equalizing mapping of the global tuberculosis research architecture. Tuberculosis (Edinb). 2015;95(4):515-22.

75. Willemsen MC, Nagelhout GE. Country differences and changes in focus of scientific tobacco control publications between 2000 and 2012 in Europe. Eur Addict Res. 2016:22(1):52-8.

76. Bennett S, Agyepong IA, Sheikh K, Hanson K, Ssengooba F, Gilson L. Building the field of health policy and systems research: an agenda for action. PLoS Med. 2011:8(8):e1001081.

77. Miro O, Montori E, Ramos X, Galicia M, Nogue S. Trends in research activity in toxicology and by toxicologists in seven European countries. Toxicol Lett. 2009:189(1):1-4.

78. Cheng T, Zhang G. Worldwide research productivity in the field of rheumatology from 1996 to 2010: a bibliometric analysis. Rheumatology (Oxford). 2013;52(9):1630-4.

79. Soteriades ES, Falagas ME. A bibliometric analysis in the fields of preventive medicine, occupational and environmental medicine, epidemiology, and public health. BMC Public Health. 2006;6:301.

80. Jang DH, Rusyniak DE. Hard impact: journal impact factor and JMT. J Med Toxicol. 2011;7(4):256-8.

81. Bird SB. Journal impact factors, $h$ indices, and citation analyses in toxicology. J Med Toxicol. 2008;4(4):261-74. 
82. Delirrad M, Rashidi A, Karimi S. A bibliometric analysis of toxicology publications of Iran and Turkey in ISI web of science. Iranian J Toxicol. 2013;6(19):735-45.

83. Fernö O. Conversation with Ove Ferno. Addiction. 1994:89(10):1215-26.

84. Zyoud SH. Dengue research: a bibliometric analysis of worldwide and Arab publications during 1872-2015. Virol J. 2016;13:78.

85. Zyoud SH, Waring WS, Al-Jabi SW, Sweileh WM, Rahhal B, Awang R. Intravenous lipid emulsion as an antidote for the treatment of acute poisoning: a bibliometric analysis of human and animal studies. Basic Clin Pharmacol Toxicol. 2016;119(5):512-9.

Submit your next manuscript to BioMed Central and we will help you at every step:

- We accept pre-submission inquiries

- Our selector tool helps you to find the most relevant journal

- We provide round the clock customer support

- Convenient online submission

- Thorough peer review

- Inclusion in PubMed and all major indexing services

- Maximum visibility for your research

Submit your manuscript at www.biomedcentral.com/submit
Biomed Central 